\title{
Cross-cultural Communication in Business Negotiations
}

\author{
Liangguang Huang \\ English Department, Zhenjiang Watercraft College of PLA \\ Zhenjiang 212003, China \\ E-mail: Blackhawk1975@126.com
}

\begin{abstract}
All communication is cultural -- it draws on ways we have learned to speak and give nonverbal messages. With the implementation of the Economic Reform and Opening policies, more and more Chinese companies do business with the foreigners. When negotiating with the delegates from different countries, cross-cultural communications play an important role. Culture differs from one another, which influences the style, the time, and the course of negotiations. If distorted, cross-cultural communications may weaken a company's position in the market, prevent it from accomplishing its objectives, and ultimately lead to failure of negotiation.
\end{abstract}

Keywords: Cross-culture, Cultural difference, Business negotiation, Negotiating style

\section{Introduction}

As business has turned more and more to an integrated world market to meet its needs, the difficulties of communicating at a global level have become increasingly widespread. Still, in an increasingly competitive world economy, it is harder for the successful business venture to conduct business exclusively within the safe confines of a single domestic business environment. With the implementation of the Economic Reform and Opening policies, China's national economy has made unprecedented strides in the last three decades. More and more Chinese products have forced their way into the international markets. There have been frequent and increasing business contacts and cooprations with foreign nationals. To secure a favorable position in the business world, executives have become growingly aware of the important roles of cross-cultural communications. As is commonly known, culture differs from one another. Their differences, which should be noted, can affect all entry strategy decisions, such as the choice of target country markets, the choice of a candidate product and its adaptation to foreign markets, the choice of an entry mode, the formation of a foreign marketing program and the control of entry operations, etc. All these decisions depend on cross-cultural communications of one sort of another. So, if distorted, cross-cultural communications may weaken a company's position in the market, prevent it from accomplishing its objectives, and ultimately lead to failure.

\section{Cultural variables}

There are many cultural variables that might hinder successful business negotiations.

\subsection{Greetings}

As the proverb goes "First impressions are most lasting". The same is true for the first word that people say when they first meet before negotiation. An appropriate greeting can not only convey the message that you are serious in establishing a cordial business relationship with your foreign counterparts, but also affect their judgment, and subsequently their business decisions on you.

As we all known, the cultures in the world are not entirely different, they have many general features in common, the so-called cultural universals. It is these cultural universals that enable the world's languages to possess more or less equivalent expressions for greetings. However, there do exist great differences in the ways that people from different cultures greet each other. It is these differences that often create problems. For example, the Chinese tend to greet each other with personal questions to show their considerations and concerns for others, but the Westerners, in their unique cultural tradition and psychology, place more value on privacy and individual liberty. They consider it decent and respectful not to nose into other people's affairs. Thus they usually fail to sense the considerations and friendliness behind many of the Chinese question-like greetings. They may even feel disgusted or offended, especially by those inquisitive idle talks.

Well begun is half done. Though good greetings don't mean half done, they do make a good start for a business contact. Their importance is self evident.

\subsection{Negotiating Styles}

Business negotiations are not games of words. They are, in fact, fierce battles of wits and tactics. To win such a battle with foreign nationals, one needs to acquaint himself with their respective negotiating style. 
The Japanese, for example, think very highly of rites, being a nation deeply influenced by the traditional Chinese culture, especially by the Confucian ideas. In negotiations, they are particular about an equal or near equal membership of the other bargaining group. If not, they will either feel slighted, even insulted or have doubt in the final say of the small membership. The Japanese also have an age-long prejudice against women. If too many business females are in the other group, they will feel uneasy or annoyed. In their biased point of view, women should stay at home, nursing the kids, tending to household chores and waiting on their husbands rather than sit at the negotiation table. This male-chauvinism may be traced to the Japanese acculturation of the Chinese feudal ethical codes, to the exact here, the three cardinal guides - ruler guides subjects, father guides son, husband guide wife. Another characteristic of the Japanese in negotiation is that they habitually don't give clear and straight forward answers. They may keep on saying "yes, yes". However, their yes doesn't mean their acceptance to the term is offered, but rather their understanding of what is said. They keep on saying Yes only for rite's sake. Still worth mentioning there is that the Japanese have more trust in personal rapport than in business contracts. This presets a sharp contrast to the Americans. So when doing business with the Japanese, you should take time and pains to establish true personal rapport and friendships. Don't count too much on contracts, they are pieces of waste paper in the eyes of the Japanese once both sides are at odds.

The United States is known as a "melting pot" with peoples from a great variety of cultures pouring into this pot. Though the different cultures are not entirely melted in this pot, some broad generalizations can still be drawn about Americans. Americans are looked on as rugged individuals who are aggressive on the negotiation table and seek to stand out "above the crowd" in their business affairs. They are generally considered straightforward, get-to-the-point business people. They are frank, light-hearted, confident, and risky in their pursuit of material gains. They value time, efficiency and laws very much. But they don't care very much for formality, rituals, and social rules. They are impressive for their "package deal" manners on the negotiation table. They are frankly expressive and like to crack jokes, sometimes to the extent of appearing disrespectful to the other group. All these character traits and business styles of the Americans are the natural results of a young nation, a great variety of cultures and a universal language.

The Russians are good at playing tricks in business negotiations. They will always try to bring down a proposed price, be it ever so low. They will try to persuade you to let off the price for a good reputation. They like to play cat and mouse with you, saying that your rival is proposing a much lower price and that your offer is in no way acceptable. They may even get to their feet and turn away from the table. However, you needn't take it to heart. They will come back, for sure. If they can get what they desire at a lower price elsewhere, they will not waste their tongue with you.

The Arabs are a typically religious group. Most of them tend to be stubborn and stiff, suspicious and conservative. In business negotiations, they usually take things in a leisurely manner and are often deliberately mystifying. They are good at bargaining. When they don't want to accept a proposed price, they simply pay no attention to it. They may even, in times of real need, bring the negotiation to an abrupt halt or break their previous promises by the excuse that it is the holy order of Allah. The wealthy Arab businessmen are usually friendly and hospitable. They may rise from the negotiation table to greet a friend or commonly unacceptable in many other cultures. But the Arabs think that they should be friendly to all their guests.

Any other countries also have their respective culture. If you want to negotiate successfully with the members from these countries, you must show your respect to their culture.

\subsection{Attitudes to time}

The perception of time is also culturally patterned. Thus, wide differences exist in people's views of time all over the world. The Americans, typical of Western cultures in general and industrialized societies in particular, view time as unilinear, so activities need be scheduled. They view time as valuable, as a commodity, a thing that can be saved, spent, or wasted. They budget their time as they budget their money. Hence their saying "Time is money". They value promptness and deplore the waste and passing of time. They don't like to be kept waiting. They would often rush into a business and their impatience is often exploited, esp. by the Japanese.

As an oriental nation, deeply influenced by Confucian ideas, the Japanese place a high value on rites and the establishment of personal rapport before really getting down to business. They usually don't grudge the time it might take them to do so. In business negotiations they will keep on saying "yes, yea" instead of a straight for word "no" to the proposals or terms they don't want to accept. Their view of time is much more flexible than that of the Americans.

The Russians are one of the nations that regard time as the cheapest of commodities and an inexhaustible resource. Bureaucratism and a dilatory style of work prevail in Russia. Russian business people habitually don't 
rush into a business negotiation unless they are in urgent need of what is offered.

In the Middle East, the Arabs typically lack a strict sense of time. The punctual Americans who insist on the meeting of deadlines will surely be left waiting. However, once a business person is finally invited into the Middle Easterner's office, the interview will last as long as necessary to transact the business, even though the next visitor may be kept waiting for what might seem an interminable time.

The Chinese look upon time as elastic, which can be stretched or contracted depending on the circumstances. Punctuality is not important, long delays are sometimes necessary before taking action. As the Chinese saying goes "Think twice before you act", although it might take them too long to think twice.

\subsection{Meanings of numbers}

The numbers are mysteriously bound up with lucks. The number " 3 " enjoys both praise and abuse alike. In Monaco, people like this number very much because they believe it will bring them prosperity. The Hong Kong people like this number, too, because in Cantonese, "3" is homophonic with "promotion". But the Europeans generally consider it ominous. "4" is commonly disliked by people in Japan, Hong Kong and China, because it means death. In Southeast Asian countries, most people like the number "6", which means "smoothness and success". Islamites are almost partial for "7", because they regard it as a holy whole number, for Allah, after having created the world in the first 6 days, took a rest on the 7th. But in Singapore, it is a negative number. In China, people have partiality for " 8 ", which means "rich". The westerners dislike the date " 13 " of any month, the day they think will bring misfortune. If it happens to be Friday, which is called "Black Friday" and will bring greater misfortune in their eyes, they avoid doing anything important. Nor do they like the number "13".

An example may help illustrate the importance of the number. An airline opened a new route in Hong Kong a few years ago. They numbered their planes " 858 " and " 859 ". To their great surprise, many passengers would rather other airlines when they learned the number of the plane they were to travel by. The company learned later that it were the numbers that mattered. In Cantonese, "58" means "not rich", while " 859 " means "rich but not long". After changing the numbers to " 888 " and " 889 ", the company found that the passengers all preferred these two lucky numbers.

\subsection{Gift-giving customs}

Both parties may present gifts each other before or after negotiation, so customs concerning gift-giving are extremely important to understand. In some cultures, gifts are expected, and failure to present them is considered an insult, whereas in other cultures, offering a gift is considered offensive.

Gift-giving is an important part of doing business in Japan. Exchanging gifts symbolizes the depth and strength of a business relationship to the Japanese. Gifts are usually exchanged at the first meeting. When presented with a gift, companies are expected to respond by doing the same in return.

In sharp contrast, gifts are rarely exchanged in Germany and are usually not appropriate, while in Belgium or the U.K., gift-giving is not a normal practice, although flowers are a suitable gift if invited to someone's home.

Likewise, the Chinese gift-giving customs differ from those of the English-speaking people. In China, when visiting someone, you should take the gift, whether wrapped or not. When you give it to the host upon leaving, he would say "No" and decline it before accepting, try to persuade visitor not to bring anything next time. It is impolite to open the gift before the guest or appear happy. Usually, the host will give something in return immediately. But in the English-speaking countries, your well-wrapped gift should give to the host just after arriving, the host accepts it by saying "thanks", and tries to convince you that he like the gift very much. With happiness, he opens the gift and pay compliment.

There are also various taboos in gift-giving customs. For instance, no gifts of food should be given to the Moslems during the month of Ramadan. No gifts of dolls will be accepted by the Arabs all through the year, because they should not cherish any other idols except Allah in their hearts. Do not repeat the gifts to the same Japanese except whiskey. Do not give gifts of the same face value to the Japanese managing director and driver alike, the former will consider it an insult. Do not present gift of clock to people in China. None of the Chinese like green hat, which means "cuckold son".

\subsection{Significance of Gestures}

The body is a powerful communication device. People around the world use body movements or gestures to convey specific messages. For example, locking ankles means anxious and tense, clenching fist means under stress, touching nose with index finger means that someone doesn't like what he is hearing, rubbing hands together means anticipating something good is about to happen, etc. These are common gestures used in every 
country.

The countries sometimes use the same gestures, but they often have very different meanings, to which should be paid attention in negotiations. The American symbol for "OK" or "Everything is right" is made by forming a circle with the thumb and index finger. In other cultures it may mean zero, as in France, money, as in Japan, or be a sign of vulgarity, as in Brazil. The familiar $\mathrm{V}$ for a victory symbol may be an insulting sign in most Europe. The familiar nodding of heads up and down indicates agreement or "Yes". In China, Japan and some other parts of the world, this motion may mean simply that the person hear what is said. In Bulgaria a nod means "No", and aside-to-aside shake of the head means "Yes". The Chinese like to touch a child's head to show affection, but in Arab countries and Thailand, it is offensive, as the head is considered most sacred.

These examples of gestures are only a few of many that could be cited. To a business person, when negotiating with the members from other countries, carelessness could make the difference between a sale and no sale, between a commission and no commission, between the success and failure.

\section{Cross-Cultural Communication Strategies}

The key to effective cross-cultural communication in business negotiation is knowledge. First, it is essential that people understand the potential problems of cross-cultural communication, and make a conscious effort to overcome these problems. Second, it is important to assume that one's efforts will not always be successful, and adjust one's behavior appropriately. It is also important to respect the negotiators and their culture.

For example, one should always assume that there is a significant possibility that cultural differences are causing communication problems, and be willing to be patient and forgiving, rather than hostile and aggressive, if problems develop. One should respond slowly and carefully in cross-cultural exchanges, not jumping to the conclusion that you know what is being thought and said.

The suggestion for heated conflicts is to stop, listen, and think, or to put it "go to the balcony" when the situation gets tense. By this it means withdraw from the situation, step back, and reflect on what is going on before you act. This helps in cross cultural communication as well. When things seem to be going badly, stop or slow down and think. What could be going on here? Is it possible I misinterpreted what they said, or they misinterpreted me? Often misinterpretation is the source of the problem.

Active listening can sometimes be used to check this out-by repeating what one thinks he or she heard, one can confirm that one understands the communication accurately. If words are used differently between languages or cultural groups, however, even active listening can overlook misunderstandings.

Often intermediaries who are familiar with both cultures can be helpful in cross-cultural communication situations. They can translate both the substance and the manner of what is said. For instance, they can tone down strong statements that would be considered appropriate in one culture but not in another, before they are given to people from a culture that does not talk together in such a strong way. They can also adjust the timing of what is said and done. Some cultures move quickly to the point; others talk about other things long enough to establish rapport or a relationship with the other person. If discussion on the primary topic begins too soon, the group that needs a "warm up" first will feel uncomfortable. A mediator or intermediary who understands this can explain the problem, and make appropriate procedural adjustments.

\section{Conclusion}

Each of the variables discussed in this module are much more complex and difficult undertaking than it is possible to convey. Any cultural ignorance or carelessness on the part of the executive might lead to communication blunder and negotiation failure.

\section{References}

Culbro R.D.and P. Herbig. (1998). Cultural differences in International Negotiating. International Journal of Value-Based Management.

David A. Victor. Cross-cultural / International Communication. [Online] Available: http:/www.referenceforbusiness.com/encyclopedia/Cos-Des/Cross-Cultural-International-Communication.html.

Michelle LeBaron. Cross-Cultural Communication. [Online] Available: http://www.beyondintractability.org/essay/cross-cultural_communication/(July 2003).

Wang, Honggeng (2005), The Business Negotiation. Beijing: The Capital Economy and Commence University Press.

Zhu, Wenjun. (1994). The Research of Modern English Language and Culture. Beijing Language Institute Press. 